\title{
Kendall M. Campbell, MD Selected as 2014 Puffer/IOM Fellow
}

\section{Jane Ireland}

The Institute of Medicine (IOM) has selected Kendall M. Campbell, MD, as the 2014 James C. Puffer, MD/American Board of Family Medicine (ABFM) Fellow. Dr. Campbell is an associate professor in the Department of Family Medicine and Rural Health and codirector for the Center for Underrepresented Minorities in Academic Medicine, Florida State University, Tallahassee.

Dr. Campbell is from the rural community of DeFuniak Springs, Florida, and was one of the first

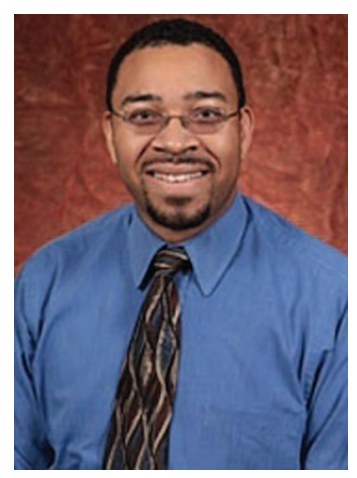
SSTRIDE (Science Students Together Reaching Instructional Diversity \& Excellence) mentors and instructors. SSTRIDE seeks to identify and encourage middle and high school students from underrepresented backgrounds, including those from rural communities. Dr. Campbell became a part of the program in 1994 while an undergraduate student and chemistry premed major at Florida A\&M University. After completing his undergraduate degree, Dr. Campbell attended the Program in Medical Sciences, a 1-year program created to help promote diversity in Florida's medical schools by attracting more students from backgrounds underrepresented

Conflict of interest: The author is the communications editor for the ABFM. in medicine and in the Florida physician workforce. After the completion of medical school, Dr. Campbell went on to become a board-certified family physician with special interests in underserved care and teaching. He is the learning center advisor for the Bridge to Clinical Medicine Master's Degree Program, a program to increase underrepresented groups in medicine, and as codirector of the Center for Underrepresented Minorities in Academic Medicine, conducts research to study issues affecting underrepresented minority faculty in medical education. Dr. Campbell sees patients at Bond Community Health Center, a community health center for the underserved.

As a Puffer/ABFM/IOM Anniversary Fellow, Kendall will receive a research stipend of $\$ 25,000$. Named in honor of James C. Puffer, MD, president and chief executive officer of the ABFM, the fellowship program enables talented, early career health policy and science scholars in family medicine to participate in the work of IOM and further their careers as future leaders in the field.

IOM Anniversary Fellows continue their main responsibilities while engaging part time over a 2-year period in the IOM's health and science policy work. A committee appointed by the president of the IOM selects fellows based on their professional accomplishments, potential for leadership in health policy in the field of family medicine, reputation as scholars, and the relevance of their expertise to the work of the IOM.

10.3122/jabfm.2015.02.140354 